Article

\title{
Optimization of Nickel-Based Catalyst Composition and Reaction Conditions for the Prevention of Carbon Deposition in Toluene Reforming
}

\author{
No-Kuk Park ${ }^{1}$, Young Jin Lee ${ }^{1}$, Byung Chan Kwon ${ }^{1}$, Tae Jin Lee ${ }^{1, *}$, Suk Hwan Kang ${ }^{2}$, \\ Bum Ui Hong ${ }^{2}$ and Taejin Kim ${ }^{3}$ \\ 1 School of Chemical Engineering, Yeungnam University, 280 Daehak-ro, Gyeongsan, Gyeonbuk 38541, Korea; \\ nokukpark@ynu.ac.kr (N.-K.P.); adk789@naver.com (Y.J.L.); bckwon79@ynu.ac.kr (B.C.K.) \\ 2 Institute for Advanced Engineering, 175 Goan-ro, Baegam-myeon, Yongin-si, Gyeongki-do 17180, Korea; \\ shkang@iae.re.kr (S.H.K.); buhong@iae.re.kr (B.U.H.) \\ 3 Gyeongbuk Institute for Regional Program Evaluation, 27 Sampoong-ro, Gyeongsan, Gyeongbuk 38542, \\ Korea; tjkim@irpe.or.kr \\ * Correspondence: tjlee@ynu.ac.kr; Tel.: +82-53-810-2519
}

Received: 31 December 2018; Accepted: 2 April 2019; Published: 5 April 2019

\begin{abstract}
In this study, nickel-based reforming catalysts were synthesized for the reforming of toluene, a major component of thinners and widely used as an organic solvent. The reaction characteristics of these catalysts were investigated by both steam reforming and auto-thermal reforming. Reforming aromatic hydrocarbons like toluene to produce synthesis gas is difficult because carbon deposition also occurs, and the deposition of carbon lowers the activity of the catalyst and causes a pressure drop during the reaction process. In order to maintain a stable reforming process, a catalytic reaction technique capable of suppressing carbon deposition is required. Steam reforming and auto-thermal reforming of toluene were used in this study, and the temperature of the catalyst bed was remarkably reduced, due to a strong endothermic reaction during the reforming process. By using scanning electric microscopy (SEM), X-ray diffraction (XRD), and temperature-programmed oxidation analysis, it is shown that carbon deposition was markedly generated due to a catalyst bed temperature decrease. In this study, optimum conditions for catalyst composition and the reforming reaction are proposed to suppress the formation of carbon on the catalyst surface, and to remove the generated carbon from the process. In addition, ceria and zirconia were added as catalytic promoters to inhibit carbon deposition on the catalyst surface, and the carbon deposition phenomena according to the catalyst's promoter content were investigated. The results showed that the carbon deposition inhibition function of $\mathrm{CeO}_{2}$, via its redox properties, is insignificant in steam reforming, but is notably effective in the auto-thermal reforming of toluene.
\end{abstract}

Keywords: toluene reforming; carbon deposition; steam reforming; auto-thermal reforming

\section{Introduction}

Recently, environmental problems associated with fine dust have become increasingly important, and various technologies for the conversion of environmental pollutants into energy, as well as for the suppression of air pollutants, have been proposed [1]. It has been reported that volatile organic compounds (VOCs), $\mathrm{NOx}, \mathrm{SO}_{2}$, and $\mathrm{NH}_{3}$ exhausted to the atmosphere can act as precursors for the formation of fine dust particles. The major anthropogenic sources of VOC emissions include gasoline and diesel vehicles, solvent use, and various industries [2]. VOCs act as precursors of fine dust, and the NOx generated in flare stacks, used in VOC treatment facilities in factories that exhaust them, can also produce fine dust. Moreover, secondary air pollutants may be generated by combustion facilities, 
such as those used for reducing the emission of organic solvents exhausted by car painting or printing factories. Many species of VOCs and hazardous air pollutants (HAPs) emitted by emission facilities can, in very small amounts, adversely affect health and the environment. In addition, individual VOCs can produce secondary pollutants, such as ozone or photochemical oxide, that can remain in the atmosphere for a long period of time, produce toxic and carcinogenic effects, and cause odors [3]. Moreover, VOCs, including toluene, are carcinogenic substances that can affect the human body and have negative effects on the nervous system and olfactory function [4].

It has been proposed that synthesis gas can be produced via a reforming reaction, thereby producing fuel for the production of heat and power through an internal combustion engine [5-8]. The production technology for synthesis gas produced by the toluene-reforming reaction proposed in this study was studied, because nitrogen oxide is exhausted during the high-temperature combustion processes used when treating chemical thinners, such as those used in painting and printing factories. Among the chemical species contained in such thinners, approximately $80 \%$ is toluene, a hydrocarbon having seven carbon atoms. Toluene can be used as a fuel in a reforming reaction that can produce hydrogen and carbon monoxide. In this study, we propose a method for reforming toluene in a catalytic reactor that can prevent carbon deposition while producing synthesis gas.

At present, thinner that is used in painting and printing factories is collected and concentrated through an adsorption process with activated carbon; subsequently, synthesis gas can be produced by reforming the recovered thinner. This study sought to produce synthesis gas for use as a fuel in an internal combustion engine by reforming toluene, a main component of thinner. For such reforming, a demonstration catalyst was prepared, and its performance evaluated.

Liquid hydrocarbons have lower binding energies in the $\mathrm{C}-\mathrm{C}$ and $\mathrm{C}-\mathrm{H}$ bonds than those of methane, so pyrolysis, along with the formation of carbon, easily occurs around $500{ }^{\circ} \mathrm{C}$. Aromatic hydrocarbons in particular have a relatively low number of hydrogens compared to aliphatic hydrocarbons; thus, carbon is formed more easily during pyrolysis. When hydrocarbons are used as fuel, carbon can be deposited on the catalyst surface (depending on the operating conditions). In the case of aromatic compounds, carbon deposition can be severe. Carbon coke is a typical catalyst deactivating substance that is generally deposited on a catalyst surface, lowering its catalytic activity [9-11]. Many researchers have attempted to suppress catalyst deactivation in a heterogeneous catalytic reaction process by using hydrocarbons as a feedstock [12-15]. In particular, since carbon nanotubes grow well on the surface of nickel, many studies have been conducted to control the steam/carbon $(\mathrm{S} / \mathrm{C}$ ) ratio, in order to suppress carbon deposition during the reforming reaction for liquid hydrocarbons using nickel catalysts. Nickel-based catalysts, such as $\mathrm{Ni} / \mathrm{Al}_{2} \mathrm{O}_{3}, \mathrm{Ni}-\mathrm{CeO}_{2} / \mathrm{Al}_{2} \mathrm{O}_{3}$, $\mathrm{Ni} / \mathrm{CeO}_{2}, \mathrm{Ni}$ /olivine, and $\mathrm{Ni} / \mathrm{C}$ have been studied.

For the inhibition of carbon deposition, low-acidity support materials and high-oxygen mobility promoters have also been studied. There have been many studies reporting on support materials and catalytic promoters for oxidizing and removing coke, and most researchers have attempted to design a catalyst that inhibits deactivation of the reforming catalyst and have investigated carbon deposition on the catalyst surface [12-24]. However, in the reforming reaction, carbon may be produced not only on the surface of the catalyst, but also, for various reasons that depend on the operating conditions, in other areas.

Typical reforming reaction behavior involves hydrocarbon pyrolysis. Since aromatic hydrocarbons have a smaller number of hydrogen atoms than olefinic and paraffinic hydrocarbons, the decomposition of aromatic compounds produces carbon rather than producing light hydrocarbons. In the reforming reaction, there is a high possibility that the pyrolysis reaction occurs in the high-temperature region inside the reactor, which, due to the formation of carbon, may cause problems during the reaction process. In addition, when the temperature in the catalyst bed drops, due to a high endothermic reaction during the reforming reaction, thermodynamic carbon formation may occur. Carbon may be formed when the temperature in a steam reforming reaction drops under $650{ }^{\circ} \mathrm{C}$. In practice, a temperature drop in the catalyst layer of a laboratory-scale microreactor, resulting from an endothermic 
reaction, can be prevented by supplying heat from an electric furnace; thus, the reaction temperature can be kept constant. However, when the reactant supply amount is increased for device scale-up, and the heat supply to the catalyst bed is insufficient, the temperature in the catalyst bed can decrease to the carbon depositional temperature. In contrast, an auto-thermal reforming reaction can be used to prevent such a temperature drop, and can reduce energy consumption by supplying a suitable amount of oxygen, so that the endothermic and exothermic reactions can occur simultaneously during the reforming reaction. In this study, carbon deposition was shown to be more effectively prevented by auto-thermal reforming than by steam reforming. In addition, the carbon deposition inhibitory effect was confirmed, examining the results obtained from a catalyst with added catalytic promoters.

\section{Experiments}

\subsection{Preparation of Nickel-Based Catalysts}

In this study, nickel-based pellet catalysts were prepared for use in the steam and auto-thermal reforming of toluene. The nickel catalyst was prepared via the impregnation method, with $10 \mathrm{wt} \%$ nickel impregnated using alumina pellets as the support. Nickel nitrate $\left(\mathrm{Ni}\left(\mathrm{NO}_{3}\right)_{2} \cdot 6 \mathrm{H}_{2} \mathrm{O}\right)$ was used as the precursor for impregnating nickel on the support. In order to prevent the sintering of nickel at high temperatures, magnesium nitrate $\left(\mathrm{Mg}\left(\mathrm{NO}_{3}\right)_{2} \cdot 6 \mathrm{H}_{2} \mathrm{O}\right)$ was used. To reduce carbon deposition on the surface of the catalyst, cerium nitrate $\left(\mathrm{Ce}\left(\mathrm{NO}_{3}\right)_{2} \cdot 6 \mathrm{H}_{2} \mathrm{O}\right)$ and zirconium nitrate $\left(\mathrm{Ce}\left(\mathrm{NO}_{3}\right)_{2} \cdot 6 \mathrm{H}_{2} \mathrm{O}\right)$ were added as precursors, so that $\mathrm{CeO}_{2}$ and $\mathrm{ZrO}_{2}$ existed as complex oxides. The promoters' contents were $\mathrm{Mg}-$-, $\mathrm{Ce}-$, and $\mathrm{Zr}$-oxides at $3 \mathrm{wt} \%, 2 \mathrm{wt} \%$, and $1 \mathrm{wt} \%$, respectively. The catalysts obtained by impregnation of nickel, magnesia, ceria, and zirconia on alumina pellets were dried at $150{ }^{\circ} \mathrm{C}$ for $12 \mathrm{~h}$, and then calcined at $750{ }^{\circ} \mathrm{C}$ for $4 \mathrm{~h}$ to be used for the reforming of toluene. $\mathrm{MgO}$ was added to suppress the high-temperature sintering of nickel, and $\mathrm{CeO}_{2}$ was added to prevent carbon deposition on the catalyst surface. $\mathrm{ZrO}_{2}$ was also added to improve the lattice oxygen mobility of $\mathrm{CeO}_{2}$.

To investigate the optimum cerium oxide content when used as a catalytic promoter, the content of cerium oxide in the nickel-based catalysts varied within the range of $2-8 \mathrm{wt} \%$. For the preparation of catalysts for assessing the effect of $\mathrm{CeO}_{2}$, the molar ratio of $\mathrm{Ce} / \mathrm{Zr}$ was fixed at 2.0, and the content of alumina used as the support was decreased as the content of the additive was increased. The effect of cerium oxide in the auto-thermal toluene-reforming reaction on the nickel catalyst was investigated by fixing the nickel oxide and magnesium oxide levels and reducing the alumina content, by increasing the amounts of Ce and Zr.

\subsection{Steam Reforming and Auto-Thermal Reforming Tests}

The steam reforming reaction for toluene was carried out in a fixed-bed catalytic reactor with a tubular reactor of 1-inch SUS316 charged with an $8 \mathrm{~g}$ pellet catalyst (diameter $\times$ height $=5 \mathrm{~mm} \times 5 \mathrm{~mm}$ ). The reactor was installed vertically in the center of the furnace. A preheater was installed at the front end of the reactor to vaporize the liquid hydrocarbons and water. The temperature of the preheater was maintained at $180{ }^{\circ} \mathrm{C}$ by a temperature controller. A condenser for collecting unreacted liquid hydrocarbons and water was installed at the rear end of the reactor. Liquid hydrocarbons and water were supplied via micro-pump. At the end of the condenser, a gas chromatograph (GC) with a thermal conductivity detector (TCD) was connected and used to analyze the composition of the dry gas. Gas composition was automatically analyzed over the full time-course of the reaction. Before initiating the reforming reaction, the catalyst was reduced for $4 \mathrm{~h}$ at $500{ }^{\circ} \mathrm{C}$ in a $50 \mathrm{vol} \% \mathrm{H}_{2}\left(\mathrm{~N}_{2}\right.$-balanced) atmosphere as a pretreatment, prior to activation of the nickel-based catalyst. The reforming experiments were carried out at $750{ }^{\circ} \mathrm{C}$ and $800{ }^{\circ} \mathrm{C}$ and the $\mathrm{S} / \mathrm{C}$ and oxygen/carbon $\left(\mathrm{O}_{2} / \mathrm{C}\right)$ ratios were 3.0 and 0.2 , respectively. Toluene and distilled water were fed at $0.5 \mathrm{cc} / \mathrm{min}$ and $1.8 \mathrm{cc} / \mathrm{min}$, respectively, and the air was added at $705 \mathrm{~mL} / \mathrm{min}$ for auto-thermal reforming. Air was not supplied in the steam reforming tests. The space velocities in the steam reforming and auto-thermal reforming reactions were fixed at $11,000 \mathrm{~mL} / \mathrm{g}_{\text {-cat }} \cdot \mathrm{h}$ and $15,000 \mathrm{~mL} / \mathrm{g}_{\text {-cat }} \cdot \mathrm{h}$, respectively. The $\mathrm{S} / \mathrm{C}$ ratio was lowered to 
2.0, and the $\mathrm{O}_{2} / \mathrm{C}$ ratio was 0.2 in the experiment to investigate the carbon deposition characteristics, according to the $\mathrm{CeO}_{2}$ promoter content on the $\mathrm{Ni}$ catalyst in the auto-thermal reforming reaction. The flow rates of toluene and distilled water, controlled using micro-pumps, were $0.5 \mathrm{cc} / \mathrm{min}$ and $1.2 \mathrm{cc} / \mathrm{min}$, respectively. The air inflow rate was fixed at $705 \mathrm{~mL} / \mathrm{min}$. The condensed water and liquid hydrocarbons were collected at the bottom of the condenser, and the fuel and water conversion amounts were measured. The flow rate of the dry gas vented to the downstream portion of the condenser, located at the outlet of the reactor, was measured by using a wet gas meter.

\subsection{Characterization of Catalysts}

To confirm the deposition of carbon on the catalyst, the surface morphology of the catalyst was observed using scanning electric microscopy (SEM; S-4100, Hitachi, Tokyo, Japan), and the deposit's crystal structure was examined by using X-ray diffraction (XRD; Rigaku, D/MAX-2500, Tokyo, Japan). The temperature programmed oxidation (TPO) test was performed using a thermo-gravimetric analyzer/differential temperature analyzer (TGA/DTA; TA instruments SDT-Q600, Champaign, IL, USA). TPO experiments were carried out within the temperature range of room temperature to $800{ }^{\circ} \mathrm{C}$, with the temperature rising at a rate of $5^{\circ} \mathrm{C} / \mathrm{min}$. The sample's weight used in the TPO tests was approximately $13 \mathrm{mg}$.

\section{Results and Discussion}

\subsection{Catalytic Activity of Nickel-Based Catalysts}

The steam reforming and auto-thermal reforming of toluene were performed over the nickel-based catalysts prepared in this study. The composition of the catalyst used in these tests was $10 \mathrm{wt} \% \mathrm{NiO}$, 3 wt $\% \mathrm{MgO}, 2$ wt $\% \mathrm{CeO}_{2}, 1$ wt $\% \mathrm{ZrO}_{2}$, and 84 wt $\% \mathrm{Al}_{2} \mathrm{O}_{3}$. Hydrogen and carbon monoxide concentrations of the reformate gases were measured during the reforming reaction at $750{ }^{\circ} \mathrm{C}$ and $800^{\circ}$ C. In the steam reforming reaction of toluene, the amounts of hydrogen and carbon monoxide differed slightly with the reaction temperature; it was $74 \%$ hydrogen and $15 \%$ carbon monoxide at $750{ }^{\circ} \mathrm{C}$, as shown in Figure 1a, and $75 \%$ hydrogen and $18 \%$ carbon monoxide at $800{ }^{\circ} \mathrm{C}$, as shown in Figure $1 \mathrm{~b}$. Although the hydrogen and carbon monoxide contents were similar at 750 and $800{ }^{\circ} \mathrm{C}$, the flow rate of the drying gas at the outlet of the reactor varied considerably with the reaction temperature. When the steam reforming reaction was carried out at 750 and $800{ }^{\circ} \mathrm{C}$, the dry gas flow rates were approximately $96 \mathrm{~L} / \mathrm{h}$ and $138 \mathrm{~L} / \mathrm{h}$, respectively. The increase in the flow rate of the dry gas with the increasing temperature of the reforming reactor indicates that gaseous hydrocarbons are present in the product gas at $750{ }^{\circ} \mathrm{C}$, even though no liquid hydrocarbon was observed in the condenser connected to the reforming reactor outlet. At $800^{\circ} \mathrm{C}$, the hydrocarbons in the gas phase were considered to have been converted to hydrogen and carbon monoxide by the reforming reaction.

On the other hand, after performing the auto-thermal reforming reaction on toluene with the same catalyst, the hydrogen and carbon monoxide contents in the drying gas flowing out to the outlet of the reforming reactor were slightly changed, according to the reaction temperature. As shown in Figure $1 \mathrm{c}, \mathrm{d}$, the hydrogen content in the dry gas was approximately $54 \mathrm{vol} \%$ and $55 \mathrm{vol} \%$ at $750{ }^{\circ} \mathrm{C}$ and $800{ }^{\circ} \mathrm{C}$, respectively, but the carbon monoxide content was $10 \mathrm{vol} \%$ and $13 \mathrm{vol} \%$, respectively. The carbon monoxide increased by approximately $3 \%$ with the increase in temperature. That result indicates that the compositional change in the fuel gas after the auto-thermal reforming of toluene was different from that after steam reforming. The auto-thermal result is considered to be due to a partial oxidation reaction by the air supplied as a reactant in the auto-thermal reforming reaction.

Hydrogen in the synthesis gas was produced at a lower concentration in the auto-thermal reforming reaction than in the steam reforming reaction, a difference that is related to the dilution of the reformate gas concentration by the nitrogen in the air supplied for auto-thermal reforming. The increase in the concentration of carbon monoxide in the auto-thermal reforming reaction was probably due to the combination of oxygen and carbon in the air. It was observed that the concentration 
of the gas remained relatively stable during the steam reforming reaction, but the concentration of the gas showed a tendency to change, in the case of the auto-thermal reforming reaction. It was concluded that the change in synthesis gas concentration can cause a temperature change inside the reactor, due to the oxygen combustion reaction.
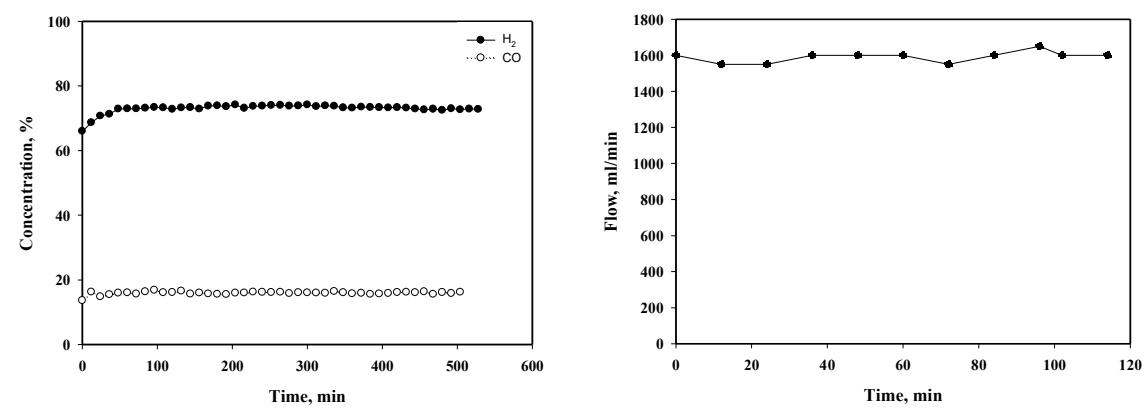

(a)
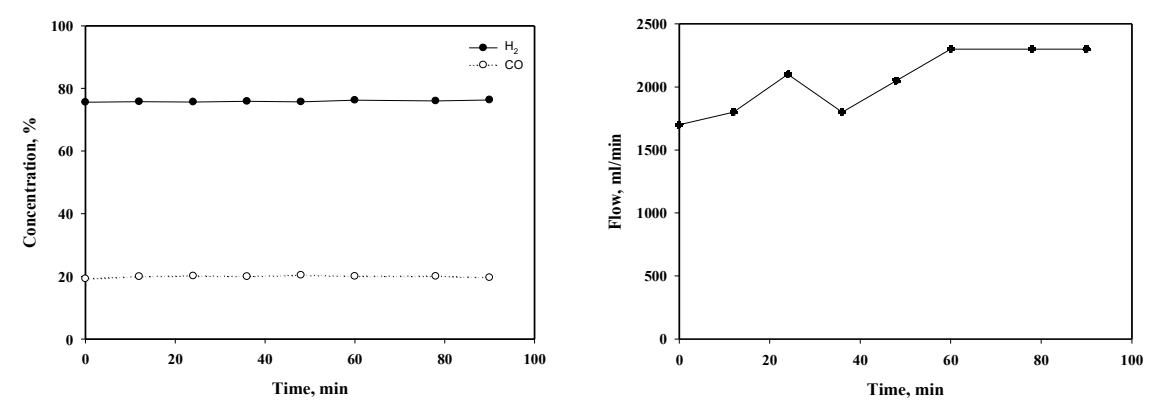

(b)
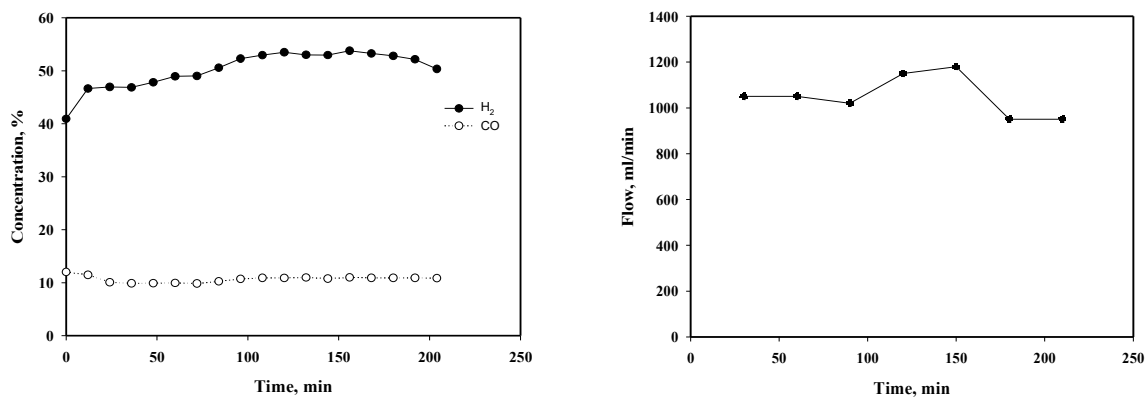

(c)
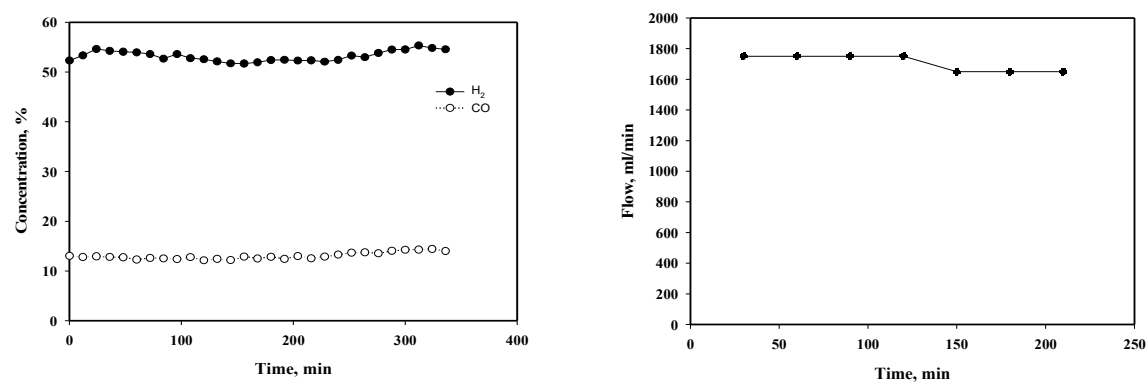

(d)

Figure 1. Concentration of $\mathrm{H}_{2}$ and $\mathrm{CO}$ in the reformate gas and the dry gas flow rates obtained by steam and auto-thermal reforming of toluene over Ni-based catalysts. (a) Steam reforming of toluene $(\mathrm{S} / \mathrm{C}=3.0)$ at $750{ }^{\circ} \mathrm{C} ;(\mathbf{b})$ steam reforming of toluene $(\mathrm{S} / \mathrm{C}=3.0)$ at $800{ }^{\circ} \mathrm{C}$; (c) auto-thermal reforming of toluene $\left(\mathrm{S} / \mathrm{C}=3.0, \mathrm{O}_{2} / \mathrm{C}=0.2\right)$ at $750^{\circ} \mathrm{C} ;(\mathbf{d})$ auto-thermal reforming of toluene $\left(\mathrm{S} / \mathrm{C}=3.0, \mathrm{O}_{2} / \mathrm{C}=0.2\right)$ at $800^{\circ} \mathrm{C}$. 
In actuality, the measured flow rate of the dry gas was half of the theoretical maximum flow rate; however, an oil component could not be confirmed in the condenser at the downstream portion of the reactor. Regardless, the results suggest that a significant amount of the incoming toluene may have been converted to carbon by pyrolysis.

Changes in catalyst bed temperature in the reactor during the steam and auto-thermal reforming of toluene were also measured. As shown in Figure 2, the reaction was started with the catalyst bed temperature established at $800{ }^{\circ} \mathrm{C}$, using an electric furnace. However, when the reaction started, the temperature of the catalyst layer dropped sharply. In the case of steam reforming, the temperature dropped to approximately $450{ }^{\circ} \mathrm{C}$, as shown in Figure 2a. A similar temperature drop was observed in the case of auto-thermal reforming, with the temperature dropping to approximately $500{ }^{\circ} \mathrm{C}$ immediately after initiation of the reaction; subsequently, the temperature tended to rise immediately, and then be maintained at approximately $700{ }^{\circ} \mathrm{C}$. In the auto-thermal reforming reaction, the temperature is recovered by strong endothermic and exothermic reactions. That is to say, the consumption heat and generated heat from the endothermic and exothermic reactions are balanced, and they attain an equilibrium according to the supply amount of hydrocarbon fuel, steam, and oxygen used as the reactants in an auto-thermal reforming reaction.

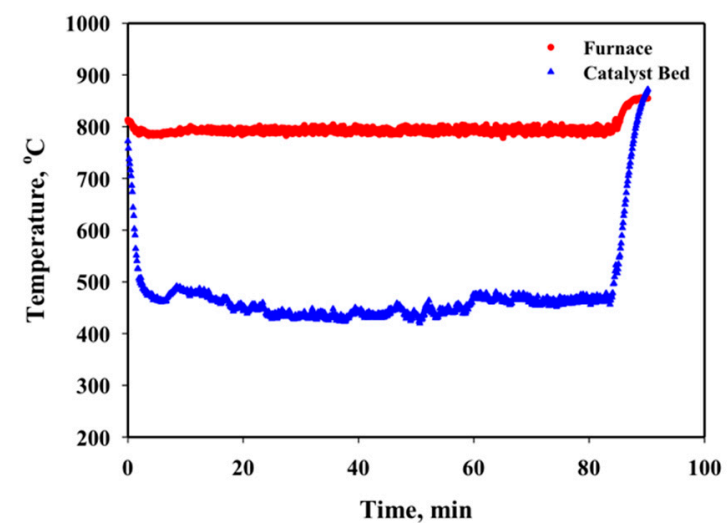

(a)

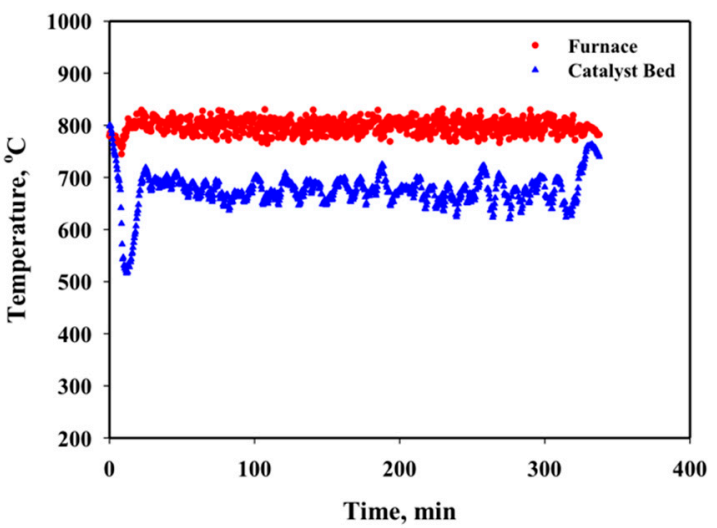

(b)

Figure 2. Temperature profile in the catalytic reactor during steam reforming and auto-thermal reforming over a Ni-Mg-Ce- $\mathrm{Zr} / \mathrm{Al}_{2} \mathrm{O}_{3}$ catalyst: (a) steam reforming of toluene $(\mathrm{S} / \mathrm{C}=3.0)$ at $800{ }^{\circ} \mathrm{C}$ and $(\mathbf{b})$ auto-thermal reforming of toluene $\left(\mathrm{S} / \mathrm{C}=3.0, \mathrm{O}_{2} / \mathrm{C}=0.2\right)$ at $800{ }^{\circ} \mathrm{C}$.

The drop in the temperature of the catalyst bed can have the effect of lowering catalytic activity of the catalyst in the reforming reaction, and if the thermodynamic temperature of the carbon formation is reached, it may have a catastrophic effect on the catalyst layer and the reactor's piping. The temperature difference of approximately $250^{\circ} \mathrm{C}$ between the steam reforming and auto-thermal reforming reactions is due to the presence of an exothermic reaction resulting from the supply of oxygen. If the temperature of the catalyst bed during the steam reforming reaction decreases, carbon deposition significantly increases, due to the pyrolysis reaction. In the case of the auto-thermal reforming reaction, the reaction temperature changed but was maintained at about $700{ }^{\circ} \mathrm{C}$; as a result, the efficiency of the reforming reaction may have been lowered. Regardless, severe carbon deposition was avoided.

\subsection{Characterization of Nickel-Based Catalyst Surface}

The surfaces of the catalyst used in the steam reforming reaction and the auto-thermal reforming reaction were also analyzed. During catalyst collection, a considerable amount of powder was observed in the sample obtained from the steam reforming reaction. In order to observe the surface state of the catalyst, the crystal structure of the sample before and after the reforming reaction was analyzed by XRD. The catalysts collected after the steam reforming reaction at $800{ }^{\circ} \mathrm{C}$ are shown in Figure 3 . As shown in Figure 3a, it was confirmed that the catalyst collected after the steam reforming reaction 
contained a considerable amount of powder particles, together with the pellet catalyst packed in the reactor. In contrast, as shown in Figure 3b, no powder was detected in the catalyst samples collected after the auto-thermal reforming reaction. Generally, when carbon deposition is severe, carbon is formed in the pores of the catalyst pellet, and the catalyst can be crushed.

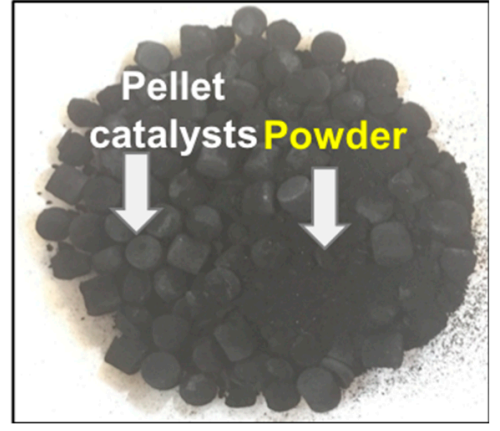

(a)

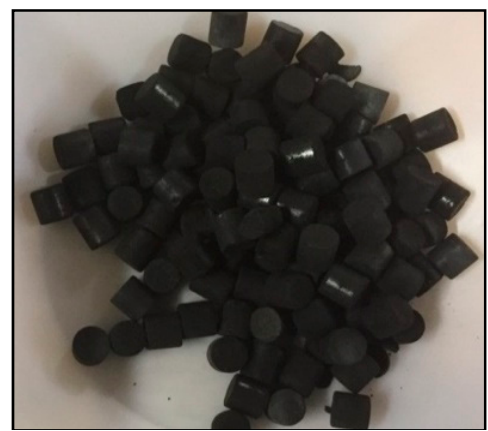

(b)

Figure 3. Image of pellet-shaped catalyst collected after (a) steam reforming at $800{ }^{\circ} \mathrm{C}, \mathrm{S} / \mathrm{C}=3.0$, and $\mathrm{O}_{2} / \mathrm{C}=0.2$; and (b) auto-thermal reforming at $800^{\circ} \mathrm{C}, \mathrm{S} / \mathrm{C}=3.0$, and $\mathrm{O}_{2} / \mathrm{C}=0.2$.

The crystal structure of the catalyst was analyzed by $\mathrm{XRD}$, in order to confirm the formation of carbon on the catalyst. $\mathrm{Ni}$ metal, $\mathrm{NiO}, \mathrm{NiAl}_{2} \mathrm{O}_{4}$, and alumina were identified, as shown in the XRD pattern in Figure 4. $\mathrm{NiO}$ is reduced to $\mathrm{Ni}$ during reduction by hydrogen in the pretreatment period before the reforming reaction, in order to activate Ni-based catalysts, and the peak pattern shown by $\mathrm{NiO}$ indicates an incompletely reduced Ni-based catalyst. The $\mathrm{NiAl}_{2} \mathrm{O}_{4}$ spinel structure is a composite metal oxide produced by bonding between alumina as the support and $\mathrm{NiO}$ as the active material at high temperatures. It has been reported that the $\mathrm{Ni}$ metal sites on the Ni-based catalysts have a high activity for reforming hydrocarbons $[20,21,23,25]$. The XRD analysis of the powders collected during catalyst sampling showed carbon peaks at 2 theta $=25^{\circ}$, with $\mathrm{Ni}, \mathrm{NiO}$, and an $\mathrm{NiAl}_{2} \mathrm{O}_{4}$ spinel, as shown in Figure $4 \mathrm{~b}$. This XRD peak ( 2 theta $=25^{\circ}$ peak) is typical of carbon and is observed in graphite [26]. Therefore, a considerable amount of carbon was formed in the toluene steam reforming reaction. Of particular note, the presence of powder particles in the steam reforming reactor means that physical cracking of the pellet-shaped catalyst due to the formation of carbon had occurred.

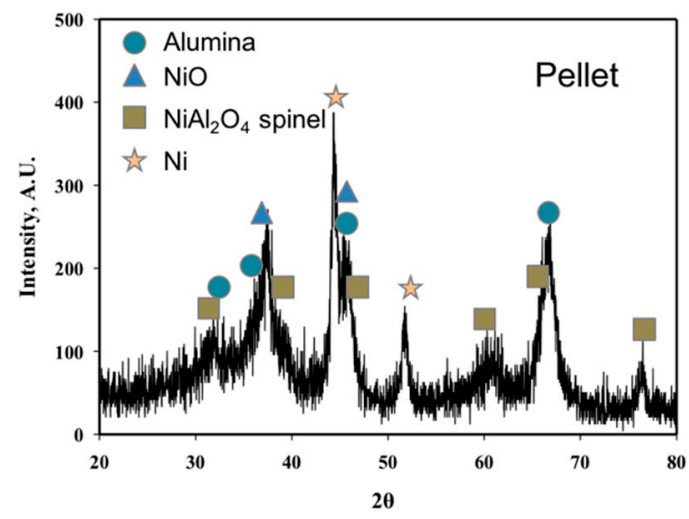

(a)

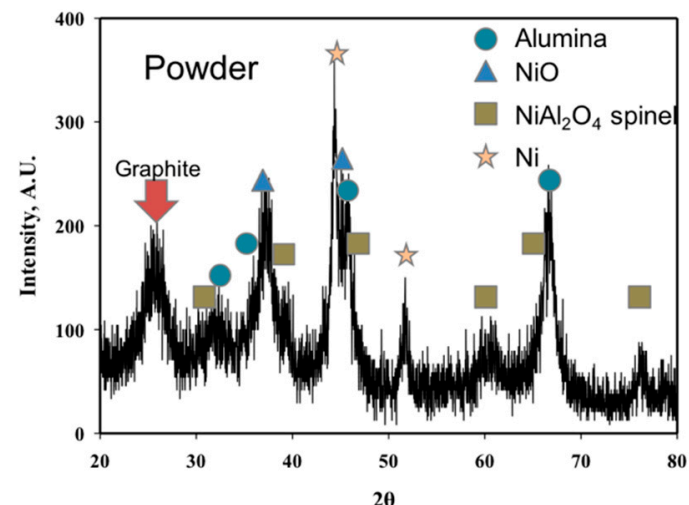

(b)

Figure 4. X-ray diffraction (XRD) patterns of (a) catalyst pellet and (b) associated powder obtained after toluene steam reforming at $800{ }^{\circ} \mathrm{C}, \mathrm{S} / \mathrm{C}=3.0$, and $\mathrm{O}_{2} / \mathrm{C}=0.2$.

The XRD patterns of the catalysts obtained after auto-thermal reforming were similar to those obtained after the steam reforming reaction, but there was no clear evidence confirming the formation of carbon in the auto-thermal reaction, as shown by the XRD patterns presented in Figure 5. This result 
may be due to the oxidation of carbon by the oxygen contained in the air supplied to the auto-thermal reforming, thereby converting the carbon to carbon monoxide or carbon dioxide. The catalyst samples collected after auto-thermal reforming did not contain powder, and no carbon deposition was observed in the XRD analysis. These results indicate that there is less carbon formation in the auto-thermal reforming reaction than in the steam reforming reaction. However, the peak intensity of the Ni metal in the catalyst was slightly decreased, and the peak intensity of $\mathrm{NiO}$ in the catalyst was slightly increased after the reforming reaction. Compared with the levels in the fresh catalyst, as shown in Figure 5a,b. This suggests that the Ni metal active sites are partially oxidized by the oxygen supplied as a reactant in the auto-thermal reforming reaction.

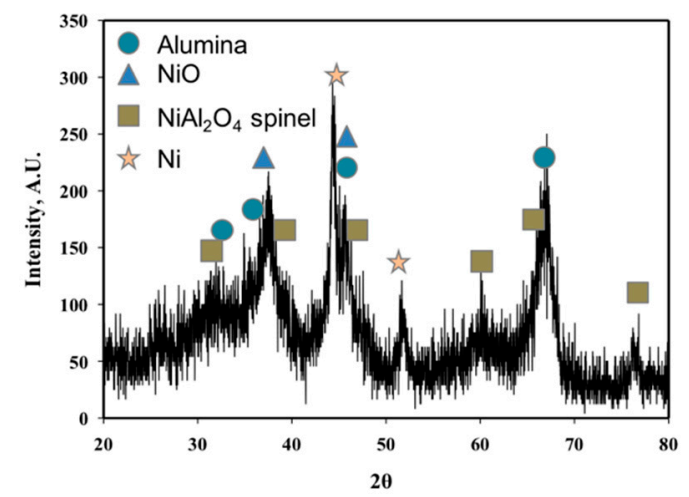

(a)

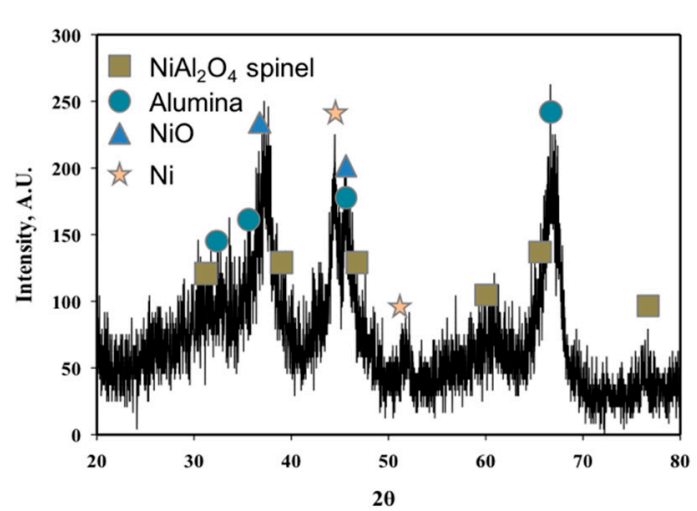

(b)

Figure 5. XRD patterns of the catalyst pellet used in toluene auto-thermal reforming, (a) fresh catalyst, and (b) used catalyst at $800{ }^{\circ} \mathrm{C}, \mathrm{S} / \mathrm{C}=3.0$, and $\mathrm{O}_{2} / \mathrm{C}=0.2$.

Observations with a scanning electron microscope to confirm carbon deposition on the surface of the catalyst showed the presence of fibrous carbon after the steam reforming reaction, as shown in Figure 6a. In contrast, carbon deposition was not observed on the surface of the catalyst after the auto-thermal reforming reaction, as shown in Figure $6 \mathrm{~b}$. The fibrous carbon grew on metal catalyst sites, such as the Ni metal site, and had a different morphology from the spherical-type carbon particles formed by the pyrolysis of hydrocarbons $[27,28]$. The catalysts used in the experiments included a promoter like $\mathrm{CeO}_{2}$ to inhibit carbon formation; regardless, the formation of fibrous carbon was clearly observed after the steam reforming of toluene. Thus, it was confirmed that the use of a catalytic promoter cannot inhibit carbon deposition. These results mean that a small amount of oxygen must be supplied for effective carbon deposition inhibition by the redox property of a promoter, such as $\mathrm{CeO}_{2}$.

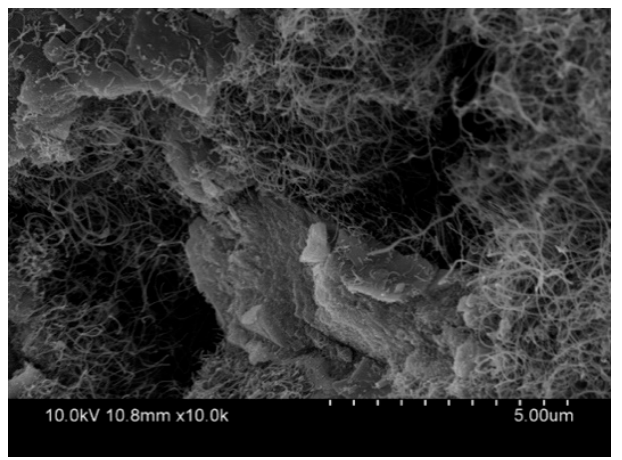

(a)

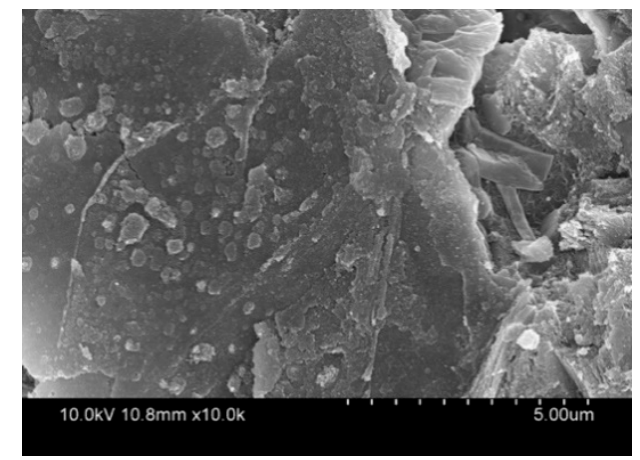

(b)

Figure 6. Scanning electric microscopy (SEM) images of Ni-based catalysts after reforming reactions: (a) steam reforming at $800{ }^{\circ} \mathrm{C}, \mathrm{S} / \mathrm{C}=3.0$, and $\mathrm{O}_{2} / \mathrm{C}=0.2$; and (b) auto-thermal reforming at $800{ }^{\circ} \mathrm{C}$, $\mathrm{S} / \mathrm{C}=3.0$, and $\mathrm{O}_{2} / \mathrm{C}=0.2$. 


\subsection{Effect of Ce-Zr-Based Additives}

In this study, it was confirmed that a significant amount of carbon can be produced during a toluene-reforming reaction. Development of a catalyst that has resistance to carbon formation is very important, because carbon deposition on the surface of the catalyst can be the main cause of deactivation of the catalyst. In the auto-thermal reforming, the carbon deposition over the surface of the catalyst could not be confirmed, and it was concluded that the generated carbon had reacted with oxygen and was removed as carbon monoxide or carbon dioxide. In order to oxidize and remove carbon on the surface of the catalyst, it is advantageous if a catalytic promoter capable of providing oxygen to the surface of the catalyst is present. Therefore, in this study, $\mathrm{CeO}_{2}$, which has redox properties, was added to the Ni-based catalysts to act as a promoter. To investigate the effect of increasing the content of $\mathrm{CeO}_{2}$ in the catalyst, the $\mathrm{CeO}_{2}$ impregnation amount was varied $(2,4,6$, and $8 \mathrm{wt} \%$ ). In addition, the $\mathrm{S} / \mathrm{C}$ ratio in the reaction was lowered to 2.0 , while the $\mathrm{O}_{2} / \mathrm{C}$ ratio was maintained at 0.2 to confirm resistance to carbon deposition. In this experiment, the reaction temperature was fixed at $800^{\circ} \mathrm{C}$.

As shown in Figure 7, the hydrogen and carbon monoxide content in the synthesis gas produced by the auto-thermal reforming changed with the $\mathrm{CeO}_{2}$ content in the Ni-based catalyst. When the content of $\mathrm{CeO}_{2}$ on the catalyst was $2.0 \mathrm{wt} \%$, the concentration of hydrogen in the dry gas at the outlet of the reactor was approximately $18 \mathrm{vol} \%$, and the concentration of carbon monoxide was approximately $13 \mathrm{vol} \%$. When the content of $\mathrm{CeO}_{2}$ increased to $4.0 \mathrm{wt} \%$ under the same conditions, the concentration of hydrogen in the dry gas was initially about $30 \mathrm{vol} \%$ and then decreased to 22 vol \% over time. However, the concentration of carbon monoxide was maintained at about $18 \mathrm{vol} \%$. When the content of $\mathrm{CeO}_{2}$ was $6.0 \mathrm{wt} \%$, the hydrogen concentration in the dry gas was maintained at approximately $34 \mathrm{vol} \%$, and the concentration of carbon monoxide was maintained at approximately $22 \mathrm{vol} \%$. Thus, the concentrations of hydrogen and carbon monoxide tended to increase as the content of $\mathrm{CeO}_{2}$ increased on the nickel catalyst in auto-thermal reforming of toluene. On the other hand, when the content of $\mathrm{CeO}_{2}$ on the catalyst was $8.0 \mathrm{wt} \%$, the concentrations of hydrogen and carbon monoxide in the dry gas decreased. At the beginning of the reforming reaction with $8.0 \mathrm{wt} \% \mathrm{CeO}_{2}$, the hydrogen concentration was maintained at about $22 \mathrm{vol} \%$ and decreased to almost the same level as that of carbon monoxide. However, the concentration of carbon monoxide remained unchanged at about 18 $\mathrm{vol} \%$. The increase in hydrogen content in these experiments means that the partial oxidation reaction of toluene is promoted by the redox property of $\mathrm{CeO}_{2}$. However, the increase in the concentration of carbon monoxide can be considered a result of the formation of carbon by the pyrolysis of toluene and the oxidation of carbon by oxygen. Nevertheless, when the content of $\mathrm{CeO}_{2}$ increased, the activity of the reforming reaction of the nickel catalyst lowered, and the oxidation reaction of carbon produced from the pyrolysis of toluene was presumed to have been maintained.

As shown in Figure 8, the formation of filament-type carbon observed in the steam reforming reaction was not observed on the surface of the catalyst after the auto-thermal reforming on the catalyst that contained $\mathrm{CeO}_{2}$. It is believed that this is due to the strong catalysis of $\mathrm{CeO}_{2}$, resulting in carbon oxidation. As the content of $\mathrm{CeO}_{2}$ increased, the surface morphology of the catalyst changed; thus, it was concluded that the added $\mathrm{CeO}_{2}$ does cover the nickel surface. Based on the results, the content of $\mathrm{CeO}_{2}$ in the catalyst for effective suppression of carbon deposition on the Ni catalyst surface should be maintained at $6 \mathrm{wt} \%$. 


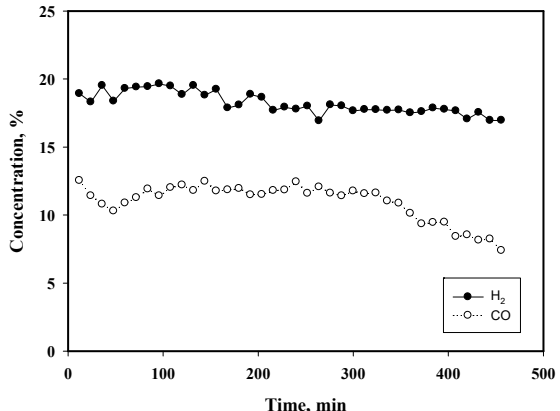

(a)

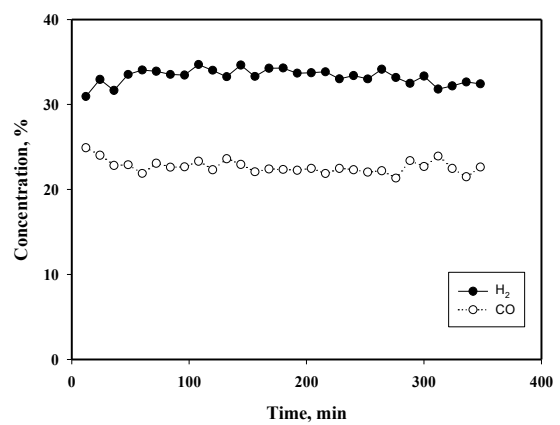

(c)

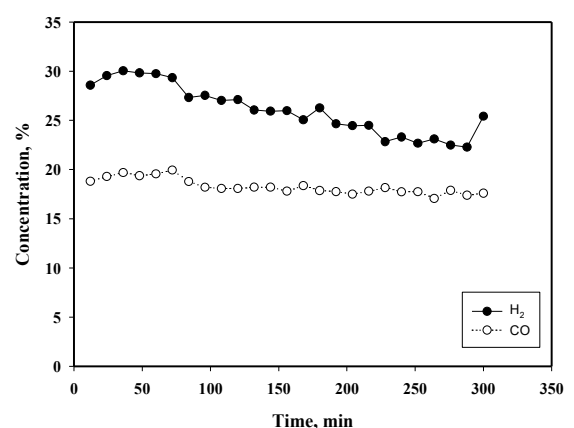

(b)

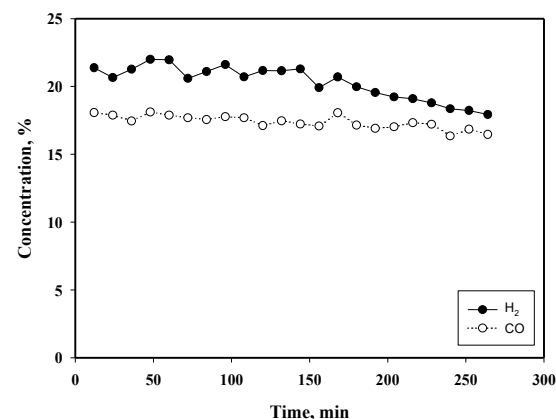

(d)

Figure 7. Concentration of $\mathrm{H}_{2}$ and $\mathrm{CO}$ in the reformate gas with the auto-thermal reforming of toluene over Ni-based catalysts impregnated with various levels of $\mathrm{CeO}_{2}$ : (a) $2 \mathrm{wt} \%$, (b) 4 wt \%, (c) 6 wt \%, and (d) $8 \mathrm{wt} \%$.
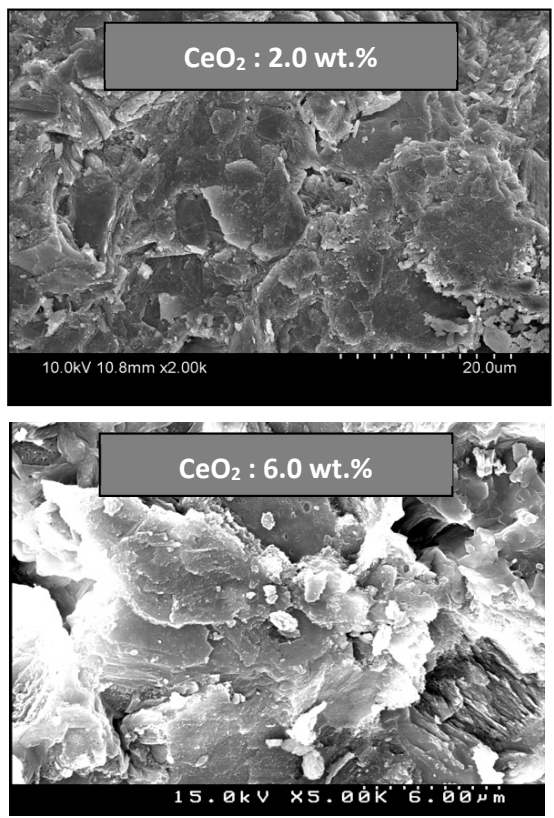
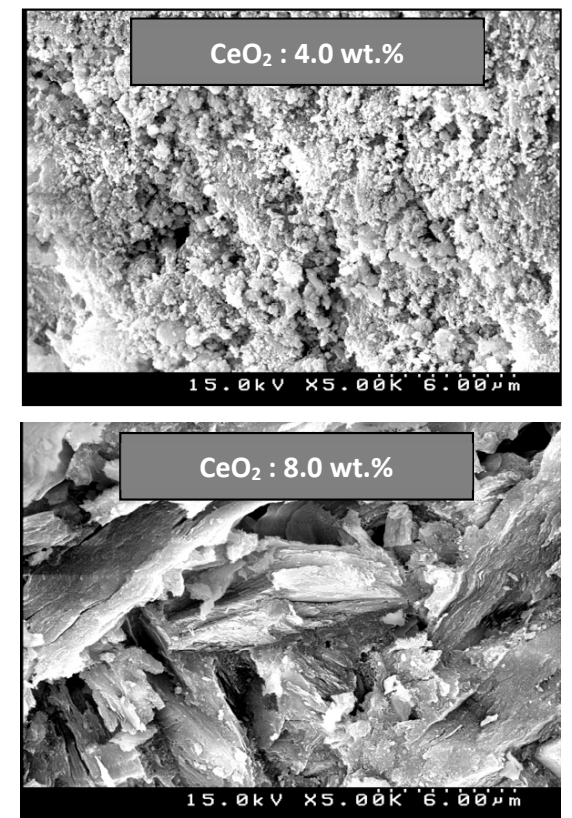

Figure 8. SEM images of Ni-based catalysts impregnated with various $\mathrm{CeO}_{2}$ content after auto-thermal reforming of toluene at $800{ }^{\circ} \mathrm{C}$.

\subsection{Temperature Programmed Oxidation Tests for Carbon Deposition on Catalysts}

The temperature programmed oxidation (TPO) test was conducted to confirm the presence of carbon deposition on the catalyst samples obtained after the steam reforming reaction. As shown in Figure 9, the powder particles and the pellet catalyst sampled after the steam reforming reaction were placed in an alumina dish for TGA testing, and the sample was then oxidized under an air 
atmosphere. The decreasing weight indicated in the thermo-gravity graph suggests the desorption of adsorbed moisture and volatile organic compounds, as well as the oxidation of the deposited carbon. As shown in Figure $9 \mathrm{a}, \mathrm{b}$, the weight of the powder sample decreased at $450{ }^{\circ} \mathrm{C}$, but the weight decreased rapidly above $500{ }^{\circ} \mathrm{C}$. The weight was maintained at about $30 \%$ of the initial weight at temperatures above $600{ }^{\circ} \mathrm{C}$. On the other hand, weight decreases in the pelletized catalyst samples were observed in the range of $500{ }^{\circ} \mathrm{C}$ to $600{ }^{\circ} \mathrm{C}$, decreased by about $5 \%$ compared to the sample's initial weight. A slight change in weight was observed within the temperature range of room temperature to $200{ }^{\circ} \mathrm{C}$, and that change was concluded to be due to the desorption of adsorbed moisture. The TPO experimental results suggest that the powder samples were comprised of carbon particles produced by the pyrolysis of toluene, indicating that carbon deposition occurs in the steam reforming reaction even under the $\mathrm{S} / \mathrm{C}=3.0$ conditions. As shown in Figure 9c, endothermic and exothermic behaviors were observed at about $600^{\circ} \mathrm{C}$, with exothermic behavior occurring after the endothermic process. The exothermic behavior is indicative of reaction heat, due to the oxidation of the deposited carbon, while the endothermic behavior is due to a decomposition reaction.

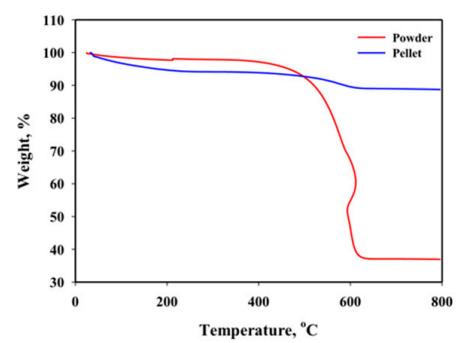

(a)

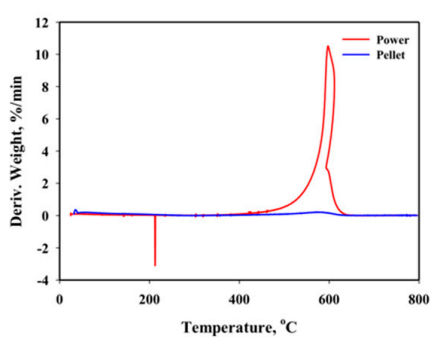

(b)

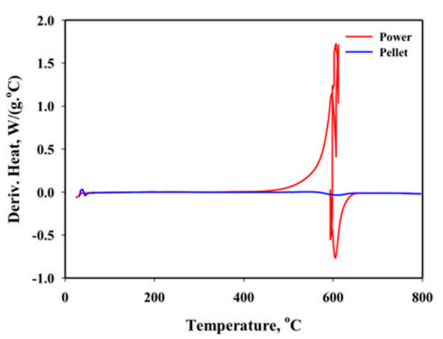

(c)

Figure 9. The results of temperature programmed oxidation (TPO) tests for powder and pellet catalyst samples, corrected after steam reforming of toluene over $\mathrm{Ni}-\mathrm{Mg}-\mathrm{Ce}-\mathrm{Zr} / \mathrm{Al}_{2} \mathrm{O}_{3}$ at $800{ }^{\circ} \mathrm{C}$ and $\mathrm{S} / \mathrm{C}=3.0$ :

(a) thermogravimetric analysis curves, (b) derived weight, and (c) derived heat.

In addition, TPO tests of the catalysts prepared with varying $\mathrm{CeO}_{2}$ content $(2,4,6$, and $8 \mathrm{wt} \%)$ on the $\mathrm{Ni}-\mathrm{Mg}-\mathrm{Ce}-\mathrm{Zr} / \mathrm{Al}_{2} \mathrm{O}_{3}$ catalyst for the purpose of carbon deposition inhibition were performed. As shown in Figure 10, a slight weight decrease was observed at approximately $600{ }^{\circ} \mathrm{C}$, and the degree of weight decrease was reduced as the amount of $\mathrm{CeO}_{2}$ impregnated on the catalyst increased. These results indicate that $\mathrm{CeO}_{2}$ used as a promoter in the auto-thermal reforming reaction does perform a carbon deposition inhibitory function. This may explain why other authors have applied auto-thermal reforming reactions for the reforming of liquid hydrocarbons. The results of the TPO test showed that the endothermic and exothermic behaviors at $600{ }^{\circ} \mathrm{C}$ were similar to those of the deposited carbon obtained through the steam reforming reaction.

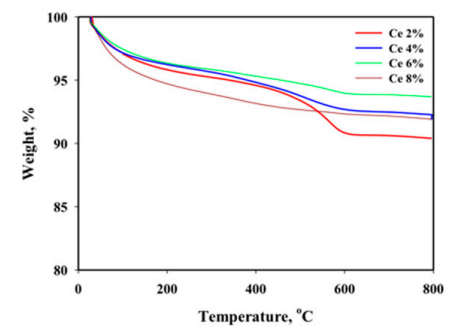

(a)

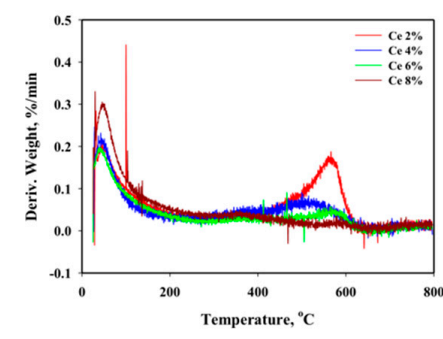

(b)

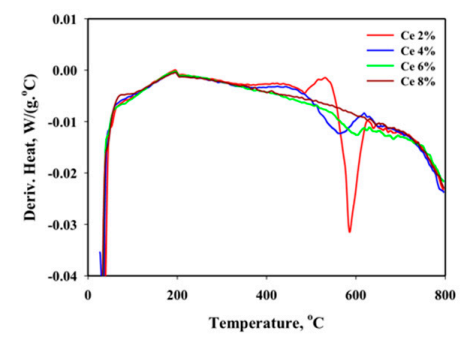

(c)

Figure 10. The results of TPO tests for pellet catalyst samples collected after auto-thermal reforming over $\mathrm{Ni}-\mathrm{Mg}-\mathrm{Ce}-\mathrm{Zr} / \mathrm{Al}_{2} \mathrm{O}_{3}$ prepared with different $\mathrm{CeO}_{2}$ contents at $800{ }^{\circ} \mathrm{C}, \mathrm{S} / \mathrm{C}=2.0$, and $\mathrm{O}_{2} / \mathrm{C}=0.2$; (a) TG thermogravimetric analysis curves, (b) derived weight, and (c) derived heat. 


\section{Conclusions}

In this study, SEM, XRD, and TPO analyses showed that carbon deposition behavior occurred over nickel-based catalysts containing $\mathrm{CeO}_{2}$ in both steam reforming and auto-thermal reforming of toluene. In toluene-reforming reactions, carbon deposition has been a serious problem. In our study, the steam reforming reaction of toluene produced a large amount of carbon deposition, but no carbon deposition was observed in the toluene auto-thermal reforming reaction. The significant amount of carbon deposition in the steam reforming reaction is attributed to the temperature drop of the catalyst bed due to a strong endothermic reaction. In the auto-thermal reforming reaction, the temperature of the catalyst bed also dropped; however, since the endothermic and exothermic reactions occur simultaneously, the temperature drop was less marked than that associated with the steam reforming reaction. Since carbon can be thermodynamically formed at a temperature below $600{ }^{\circ} \mathrm{C}$, a significant temperature drop in the reforming reaction must be inhibited when a nickel-based catalyst is used. Many previous studies have used various catalytic promoters to inhibit carbon deposition, and it has been reported that such promoters can have a significant effect. In this study, it was confirmed that a $\mathrm{CeO}_{2}$ promoter can inhibit carbon deposition on the catalyst surface. However, it was concluded that the catalytic promotive activity of ceria inhibited the deposition of carbon more effectively in the auto-thermal reforming reaction than in the steam reforming reaction. Although carbon deposition can be prevented by adding catalytic promoters to catalysts, temperature maintenance inside the catalytic reactor is very important, because the formation of carbon cannot be prevented in the presence of a catalytic promoter when there is a significant and prolonged temperature drop in the reaction.

Author Contributions: Conceptualization, N.-K.P. and T.J.L.; Methodology, N.-K.P.; Validation, N.-K.P., S.H.K., B.U.H. and T.J.L.; Formal analysis, Y.J.L.; Investigation, Y.J.L. and B.C.K.; Writing-original draft preparation, N.-K.P.; Writing-review and editing, T.K.; Visualization, Y.J.L and B.C.K.; Supervision, Project administration, and Funding acquisition, T.J.L.; All authors read and approved the final manuscript.

Funding: This research was funded by Yeungnam University, grant number 216A380152.

Conflicts of Interest: The authors declare no conflict of interest.

\section{References}

1. Swierczynski, D.; Courson, C.; Kiennemann, A. Study of steam reforming of toluene used as model compound of tar produced by biomass gasification. Chem. Eng. Process. 2008, 47, 508-513. [CrossRef]

2. Zhang, R.; Wang, G.; Guo, S.; Zamora, M.L.; Ying, Q.; Lin, Y.; Wang, W.; Hu, M.; Wang, Y. Formation of Urban Fine Particulate Matter. Chem. Rev. 2015, 115, 3803-3855. [CrossRef] [PubMed]

3. Song, B.-J.; Lee, S.-M.; Cho, G.-J.; Cho, J.-G.; You, P.-J.; Kim, G.-G. VOC/HAPs Emission Characteristics \& Adsorption Evaluation for Paint Products in Busan Area. J. Korea Soc. Environ. Eng. 2012, 34, 316-325.

4. Amagai, T. Measurement of anthropogenic VOCs and their impact on environment. Environ. Nat. Resour. J. 2011, 9, 1-5.

5. Owusu, P.A.; Asumadu-Sarkodie, S. A review of renewable energy sources, sustainability issues and climate change mitigation. Cogent Eng. 2016, 3, 1167990. [CrossRef]

6. Benson, S.M.; Bennaceur, K.; Cook, P.; Davison, J.; de Coninck, H.; Farhat, K.; Ramirez, C.A.; Simbeck, D.; Surles, T.; Verma, P.; et al. "Carbon Capture and Storage" Global Energy Assessment-Toward a Sustainable Future; Cambridge University Press: Cambridge, UK, 2012; pp. 993-1068.

7. Yu, K.M.K.; Curcic, I.; Gabriel, J.; Tsang, S.C.E. Recent Advances in $\mathrm{CO}_{2}$ Capture and Utilization. ChemSusChem 2018, 1, 893-899. [CrossRef] [PubMed]

8. Zhao, B.; Zhang, X.; Chen, L.; Qu, R.; Meng, G.; Yi, X.; Sun, L. Steam reforming of toluene as model compound of biomass pyrolysis tar for hydrogen. Biomass Bioenergy 2010, 34, 140-144. [CrossRef]

9. Bartholomew, C.H. Carbon Deposition in Steam Reforming and Methanation. J. Catal. Rev. Sci. Eng. 1982, 24, 67-112. [CrossRef]

10. Rostrup-Nielsen, J.; Trimm, D. Mechanisms of carbon formation on nickel-containing catalysts. J. Catal. 1977, 48, 155-165. [CrossRef] 
11. Son, I.H.; Lee, S.J.; Song, I.Y.; Heon, W.S.; Jung, I.; Yun, D.J.; Jeong, D.W.; Shim, J.-O.; Jang, W.-J.; Roh, H.-S. Study on coke formation over $\mathrm{Ni} / \mathrm{r}-\mathrm{Al}_{2} \mathrm{O}_{3}, \mathrm{Co}-\mathrm{Ni} / \mathrm{r}-\mathrm{Al}_{2} \mathrm{O}_{3}$, and $\mathrm{Mg}-\mathrm{Co}-\mathrm{Ni} / \mathrm{r}-\mathrm{Al}_{2} \mathrm{O}_{3}$ catalysts for carbon dioxide reforming of methane. Fuel 2014, 136, 194-200. [CrossRef]

12. Wang, Z.; Cao, X.-M.; Zhu, J.; Hu, P. Activity and coke formation of nickel and nickel carbide in dry reforming: A deactivation scheme from density functional theory. J. Catal. 2014, 311, 469-480. [CrossRef]

13. Yoon, S.; Kang, I.; Bae, J. Effect of ethylene on carbon formation in diesel autothermal reforming. Int. J. Hydrog. Energy 2008, 33, 4780-4788. [CrossRef]

14. Lee, Y.J.; Jeong, Y.H.; Kwon, B.C.; Park, N.-K.; Lee, K.Y.; Lee, T.J.; Kang, S.H.; Hong, B.; Kim, H. Investigation of Process Behavior by Carbon Formation in Steam Reforming of Toluene. J. Energy Clim. Chang. 2017, 12, $136-143$.

15. Lakhapatri, S.L.; Abraham, M.A. Deactivation due to sulfur poisoning and carbon deposition on $\mathrm{Rh}-\mathrm{Ni} / \mathrm{Al}_{2} \mathrm{O}_{3}$ catalyst during steam reforming of sulfur-doped n-hexadecane. App. Catal. A Gen. 2009, 364, 113-121. [CrossRef]

16. Jaworski, Z.; Pianko-Oprych, P. A Comparative Thermodynamic Study of Equilibrium Conditions for Carbon Deposition from Catalytic C-H-O Reformates. Energies 2018, 11, 1177. [CrossRef]

17. Tao, J.; Zhao, L.; Dong, C.; Lu, Q.; Dahlquist, E. Catalytic Steam Reforming of Toluene as a Model Compound of Biomass Gasification Tar Using Ni-CeO2/SBA-15 Catalysts. Energies 2013, 6, 3284-3296. [CrossRef]

18. Zhang, R.; Wang, H.; Hou, Z. Catalytic reforming of toluene as tar model compound: Effect of Ce and Ce-Mg promoter using Ni/olivine catalyst. Chemosphere 2014, 97, 40-46. [CrossRef] [PubMed]

19. Lakhapatri, S.L.; Abraham, M.A. Analysis of catalyst deactivation during steam reforming of jet fuel on Ni-(PdRh)/r- $-\mathrm{Al}_{2} \mathrm{O}_{3}$ catalyst. Appl. Catal. A Gen. 2011, 405, 149-159. [CrossRef]

20. Szijjarto, G.P.; Paszti, Z.; Sajo, I.; Erdohelyi, A.; Rannoczi, G.; Tompos, A. Natural of the active sites in $\mathrm{Ni} / \mathrm{MgAl}_{2} \mathrm{O}_{4}$-based catalysts designed for steam reforming of ethanol. J. Catal. 2013, 305, 290-306. [CrossRef]

21. Kim, D.H.; Ruy, J.W.; Choi, E.H.; Gong, G.T.; Lee, H.; Lee, B.G.; Moon, D.J. Production of synthesis gas by autothermal reforming of iso-octane and toluene over metal modified Ni-based catalyst. Catal. Today 2008, 136, 266-272. [CrossRef]

22. Kaila, R.K.; Krause, A.O.I. Autothermal reforming of simulated gasoline and diesel fuels. Int. J. Hydrog. Energy 2006, 31, 1934-1941. [CrossRef]

23. Kaila, R.K.; Gutierrez, A.; Korhonen, S.T.; Krause, A.O.I. Autothermal reforming of n-dodecane, toluene, and their mixture on mono- and bimetallic noble metal zirconia catalysts. Catal. Lett. 2007, 115, 70-78. [CrossRef]

24. DuBois, T.G.; Nieh, S. Selection and performance comparison of jet fuel surrogates for autothermal reforming. Fuel 2011, 90, 1439-1448. [CrossRef]

25. Fauteux-Lefebvre, C.; Abatzoglou, N.; Blanchard, J.; Gitzhofer, F. Steam reforming of liquid hydrocarbons over a nickel-alumina spinel catalyst. J. Power Sources 2010, 195, 3275-3283. [CrossRef]

26. Li, Z.Q.; Lu, C.J.; Xia, Z.P.; Zhou, Y.; Luo, Z. X-ray diffraction patterns of graphite and turbostratic carbon. Carbon 2007, 45, 1686-1695. [CrossRef]

27. Chen, P.; Zhang, H.-B.; Lin, G.-D.; Hong, Q.; Tasi, K.R. Growth of carbon nanotubes by catalytic decomposition of $\mathrm{CH}_{4}$ or $\mathrm{CO}$ on a Ni-MgO catalyst. Carbon 1997, 35, 1495-1501. [CrossRef]

28. Baker, R.T.K.; Barber, M.A.; Harris, P.S.; Feates, F.S.; Waite, R.J. Nucleation and growth of carbon deposits from the nickel catalyzed decomposition of acetylene. J. Catal. 1972, 26, 51-62. [CrossRef]

(C) 2019 by the authors. Licensee MDPI, Basel, Switzerland. This article is an open access article distributed under the terms and conditions of the Creative Commons Attribution (CC BY) license (http://creativecommons.org/licenses/by/4.0/). 